\title{
PARODOXOS NA AUTODESCRIÇÃO DO SISTEMA DO DIREITO: CORRUPÇÃO SISTÊMICA E O ATIVISMO JUDICIAL
}

\author{
PARODOXES OF THE SELF-DESCRIPTION OF THE SYSTEM OF LAW: \\ SYSTEMIC CORRUPTION AND JUDICIAL ACTIVISM
}

\section{PARODOXOS EN LA AUTODESCRIPCIÓN DEL SISTEMA DEL DERECHO: CORRUPCIÓN SISTÉMICA Y EL ACTIVISMO JUDICIAL}

\author{
RAFAEL LAZZAROTTO SIMIONI \\ http://orcid.org/0000-0002-8484-4491 / http://lattes.cnpq.br/0651879354342863 / simioni2010@gmail.com \\ Faculdade de Direito do Sul de Minas, FDSM. \\ Pouso Alegre, MG, Brasil.
}

\author{
João PaUlo Salles Pinto \\ http://orcid.org/0000-0002-7374-8736 / http://lattes.cnpq.br/1869048059845984 / jpsalles9@gmail.com \\ Faculdade de Direito do Sul de Minas, FDSM. \\ Pouso Alegre, MG, Brasil.
}

\begin{abstract}
RESUMO
As noções de corrupção sistêmica do direito e de ativismo judicial, trabalhadas no Brasil, em especial, por Marcelo Neves, Lenio Luiz Streck e outros, constituem-se em formas de distinções que escondem um paradoxo. Neste diapasão, a forma de uma observação de segunda ordem feita a partir do método pragmático sistêmico luhmanniano, permite uma concepção destes conceitos de modo distinto. Objetiva-se, portanto, tendo em vista uma metodologia revisional bibliográfica, realizar uma releitura com base na teoria dos sistemas sociais autopoiéticos de Niklas Luhmann, para verificar, no nível da observação de segunda ordem, a forma, a função e o paradoxo que tais conceitos procuram realizar na comunicação jurídica brasileira. Neste sentido, parte o presente trabalho da problemática de se é possível explicitar que as construções teóricas de corrupção sistêmica e de ativismo judicial estariam ligadas a uma realização relacional autodescritiva do sistema jurídico. Assim, a pesquisa conclui que tais conceitos se tratam de uma possível reflexão do sistema jurídico no nível da sua autodescrição contemporânea.
\end{abstract}

Palavras-chave: Ativismo Judicial; Autodescrição; Corrupção Sistêmica; Paradoxo; Teoria dos Sistemas

\begin{abstract}
The notions of systemic corruption of the law and of judicial activism, worked in Brazil, especially by Marcelo Neves, Lenio Luiz Streck and others, constitute a form of distinction that hides a paradox. In this tuning fork, the form of a second-order observation made from the Luhmann systemic pragmatic method allows a conception of these concepts in a different way. In order to verify, at the level of second-order observation, the form, the function and the paradox that such a research is based on the theory of autopoietic social systems of Niklas Luhmann. concepts in Brazilian legal communication. In this sense, the present work deals with the problem of whether it is possible to make explicit that the theoretical constructions of systemic corruption and judicial activism would be linked to a self-describing relational realization of the legal system. Thus, the research concludes that such concepts are a possible reflection of the legal system at the level of its contemporary self-description.
\end{abstract}

Keywords: Judicial Activism; Self-description; Systemic Corruption; Paradox; Theory of Systems. 


\section{RESUMEN}

Las nociones de corrupción sistémica del derecho y de activismo judicial, trabajadas en Brasil, en especial, por Marcelo Neves, Lenio Luiz Streck y otros, se constituyen en una forma de distinción que esconde una paradoja. En este diapasón, la forma de una observación de segunda orden hecha a partir del método pragmático sistémico luhmanniano, permite una concepción de estos conceptos de modo distinto. Se pretende, por lo tanto, tener en vista una metodología de revisión bibliográfica, realizar una relectura basada en la teoría de los sistemas sociales 'autopoiéticos' de Niklas Luhmann, para verificar, en el nivel de la observación de segunda orden, la forma, la función y la paradoja que tales los conceptos buscan realizar en la comunicación jurídica brasileña. En este sentido, parte el presente trabajo de la problemática de si es posible explicitar que las construcciones teóricas de corrupción sistémica y de activismo judicial estarían ligadas a una realización relacional autodescriptiva del sistema jurídico. Así, la investigación concluye que tales conceptos se tratan de una posible reflexión del sistema jurídico en el nivel de su autodescripción contemporánea.

Palabras clave: Activismo Judicial; autodescripción; Corrupción Sistémica; paradoja; Teoría de los Sistemas.

\section{SUMÁRIO}

INTRODUÇÃO; 1 A METODOLOGIA SISTÊMICA LUHMANNIANA; 2 A AUTODESCRIÇÃO NO SISTEMA JURÍDICO; 3 CORRUPÇÃO SISTÊMICA E ATIVISMO JUDICIAL NA AUTODESCRIÇÃO SISTÊMICA; CONCLUSÃO; REFERÊNCIAS.

\section{INTRODUÇÃO}

As noções de corrupção sistêmica do direito e de ativismo judicial, trabalhadas no Brasil, em especial, por Marcelo Neves, Lenio Luiz Streck e outros, constituem-se em formas de distinções que procuram invisibilizar um paradoxo. Neste sentido, a realização de uma observação de segunda ordem operada a partir do método pragmático sistêmico luhmanniano, permite, não obstante, uma concepção de corrupção sistêmica do direito brasileiro e de ativismo judicial de um modo diferente. Trata-se, neste contexto, de uma possível reflexão do sistema jurídico no nível da sua autodescrição. Igualmente, as construções de corrupção sistêmica e ativismo judicial, no âmbito da comunicação jurídica brasileira, possuem também relações com as condições de possibilidade de se controlar o uso de referências de sentido e com a própria função da argumentação no sistema jurídico.

Dessa maneira, o deslocar da observação de primeira ordem e também de segunda ordem, realizado, sobretudo, por aqueles que disputam paradigmas em torno da possiblidade atual e contingente de uma autodescrição do sistema, possibilita, sem embargo, explicitar o conteúdo paradoxal e funcional envolvido, bem como o que esses conceitos desempenham para a comunicação da sociedade.

Nesse ínterim, parte o presente trabalho do questionamento de se é possível explicitar com base no pressuposto pragmático sistêmico luhmanniano que os conceitos de corrupção 
sistêmica e de ativismo judicial estariam ligados a uma realização autodescritiva contingencial do sistema jurídico. Portanto, a corrupção e o ativismo judicial seriam uma construção reflexiva de observadores na autodescrição do sistema? Qual a função e a condição de possiblidade que as noções de corrupção sistêmica e ativismo judicial realizam na comunicação do direito brasileiro? Que tipo de paradoxo as construções de corrupção e de ativismo judicial visam invisibilizar?

De fato, essas indagações abrem a possibilidade de uma discussão que envolve tanto a questão de uma possível falta de diferenciação funcional do direito no Brasil, quanto à questão da sobreposição de códigos sistêmicos. Além disso, ela permite uma releitura da definição luhmanniana da autopoiese dos sistemas sociais como uma relação operativa entre autodescrição e auto-observação.

Objetiva-se, portanto, realizar uma releitura relacional da corrupção sistêmica e do ativismo judicial com base na teoria dos sistemas de Niklas Luhmann, para verificar, no nível da observação de segunda ordem, a forma, a função e o paradoxo que esses conceitos desempenham na comunicação jurídica brasileira.

Assim sendo, com base em uma metodologia analítica e técnica de pesquisa bibliográfica, a pesquisa convoca alguns conceitos da teoria dos sistemas sociais autopoiéticos de Niklas Luhmann, em especial, aqueles relacionados à forma, observação de segunda ordem, função, paradoxo, comunicação, autodescrição e autopoiese.

Para serem alcançados os resultados, a pesquisa parte primeiramente de uma discussão sobre a metodologia construtivista sistêmica luhmanniana, de maneira que, em um segundo momento, analisaremos os conceitos de autodescrição sistêmica, de corrupção sistêmica e de ativismo judicial em uma relação operativa, para, ao final, explicitar uma releitura destas construções, visto que os observaremos, já no aspecto conclusivo do trabalho, como situação comunicacional que permite a invisibilização do paradoxo do direito na autodescrição sistêmica contemporânea.

\section{A METODOLOGIA SISTÊMICA LUHMANNIANA}

Quando se procura utilizar como alicerce investigativo a metodologia pragmática sistêmica ${ }^{1}$ trabalhada por Niklas Luhmann, parte-se da premissa do descrever da sociedade, por conseguinte, do direito, tendo em vista uma forma de observação construtivista de natureza

${ }^{1}$ ROCHA, Leonel Severo. Epistemologia Jurídica e Democracia. São Leopoldo: Unisinos, 1998. 
autológica $^{2}$, de modo que se visa no presente artigo explicitá-los sob o enfoque autopoiético sistêmico e, portanto, mostrá-los sendo observáveis como objeto de seu próprio operar. ${ }^{3}$

Importante relatar que para Luhmann, por sistema, não se compreende uma unidade dotada de homogeneidade ou regularidade lógica que, por conseguinte, estabelece uma ordem em relação ao resto. Tampouco, como formas sociais institucionalizadas que se diferenciam das outras formas sociais "espontâneas" ou "naturais", como sustenta boa parte da teoria crítica (Habermas, por exemplo ${ }^{4}$ ). "Luhmann fala de sistema quando uma conexão de operações consegue se fechar excluindo todo o resto e, dessa forma, reproduzir-se e continuar a própria existência até que esteja em condições de fazê-lo." 5

Neste diapasão, considerando a sociedade e o direito vistos a partir de si mesmos, isto é, no que tange às suas operações, observações e funções recursivas, a teoria dos sistemas sociais autopoiéticos de Niklas Luhmann parte da busca por ampliar o seu próprio potencial para a complexidade. Dessa maneira é que se procura interpretar os atos mais discrepantes sob o enfoque de abstração de conceitos $^{6}$ e insights das ciências naturais e aplicadas ${ }^{7}$, o que justifica a utilização de conceitos como: forma, observação de segunda ordem, autodescrição, paradoxo, função e de autopoiese.

Por conseguinte, como já mencionado, o referencial teórico selecionado tem por norte uma conceituação autodescritiva da sociedade e do direito sob um foco construtivista radical $^{8} \mathrm{e}$

\footnotetext{
2 "Desse modo, uma teoria que trabalha com a distinção entre operação e observação é sempre uma teoria autológica. Isso significa que ela produz uma descrição que, como operação e observação, diz respeito a si mesma, razão pela qual é a partir de si própria que pode efetuar sua verificação ou, quando menos, não pode ser refutada ao supor a si própria." (LUHMANN, Niklas. Das Recht der Gesellschaft. Frankfurt am Main: Suhrkamp, 1993. p. 68).

${ }^{3}$ Neste sentido, diz Luhmann: "Nem o Estado, nem razão, nem a história legitimam o direito. Deve haver teorias que proponham, tanto hoje como no passado. Mas, se são descritas como autodescrições, exige-se delas uma inserção ao modus do observador de segunda ordem. Devem aprender a pensar nelas próprias como autodescrições de um sistema que descreve a si mesmo. De outro modo, convertem-se em algo anacrônico (esta é umas das mais significativas realizações da teoria jurídica de Jürgen Habermas, que justamente demonstra o caráter anacrônico de todo recurso à história natural, aos princípios morais ou à razão pratica)". (LUHMANN, Niklas. Das Recht der Gesellschaft. Frankfurt am Main: Suhrkamp, 1993. p. 724).

${ }^{4}$ Ver nesse sentido: HABERMAS, Jürgen. Teoria do Agir Comunicativo. São Paulo: Martins Fontes, 2012. vol. 02.

${ }^{5}$ CORSI, Giancarlo. Levando o indivíduo a sério: a relação indivíduo-sociedade na teoria dos sistemas. Tempo soc., São Paulo, v. 27, n. 2, p. 181-198. Dec. 2015. Disponivel em: http://www.scielo.br/ scielo.php?script=sci_arttext\&pid=S0103-20702015000200181\&lang=pt. Accesso em: 20 maio 2019. doi: http://dx.doi.org/10.1590/0103-2070201529.

${ }^{6}$ LUHMANN, Niklas. Das Recht der Gesellschaft. Frankfurt am Main: Suhrkamp, 1993. p.18.

7 LUHMANN, Niklas. Das Recht der Gesellschaft. Frankfurt am Main: Suhrkamp, 1993.

${ }^{8}$ De acordo com Ernest Von Glasersfeld, autor que se atribui ser responsável pelo termo "Construtivismo Radical”, este pode ser resumido em duas noções básicas: o conhecimento não é passivamente recebido através dos sentidos ou por meio de comunicação, mas é ativamente construído pelo sujeito cognoscente,
} 
anti-regionalista. Realiza-se, consequentemente, uma espécie de observação da sociedade e do direito a partir deles mesmos (uma observação da sociedade para a sociedade e uma observação do direito para o direito), ou seja, uma observação de como o observador operaciona seus conceitos, bem como encobre/inviabiliza criativamente, de certa maneira, tautologias. Portanto, analisa-se com o suporte de uma observação que tem por função descrever as observações por distinções, em especial, das auto-observações e das autodescrições. ${ }^{9}$

Tal forma de observação, que parte sempre de uma distinção entre dois lados e pergunta pela função e pelas condições de possibilidade, isto é, pelo "como é" (wie-fragen), $e$ não pelo o "que é" (was-fragen) ${ }^{10}$, tem origem na concepção dos sistemas autorreguladores da área da cibernética, visto que tem como premissa que aprendizagem (cognição) é tida por um processo de auto-organização sistêmico. Desse modo, compreende-se que só podemos ter acesso àquilo que o próprio sistema constrói em sua própria distinção ${ }^{11}$, bem como tendo em conta suas operações.

Assim, sem embargo, constata-se que a presente metodologia é, de certa forma, dotada de certa propensão a descrever “incertezas analíticas", de modo que tende a explicitar a construção dos observadores ${ }^{12}$, certo de que entende que todo conhecimento e toda realidade é sempre uma realidade de um observador, e não um dado ontológico, uma realidade objetiva, um pretexto a priori (seja empírico ou racional).

Reforça-se, em função de tais constatações, a verificação de que o sistema só pode operar no sistema e não no ambiente e, portanto, que “somente o próprio direito pode dizer o

bem como a função da cognição é adaptativa e serve para a organização do sujeito de seu mundo experiencial, e não para a descoberta de uma realidade objetiva. Ver neste sentido: GLASERSFELD, Von Ernest. Aspects of constructivism: Vico, Berkeley, Piaget. In: M. Larochelle (Ed.), Key works in radical constructivism. Sense Publishers, 2009. Contudo, Luhmann trabalha em aspectos mais amplos, ou seja, "nessa epistemologia, não devem ser entendidos apenas sistemas especialistas em cognição, mas sistemas de todo o tipo, que estabeleçam observações autoproduzidas a fim de regular sua relação como ambiente." (LUHMANN, Niklas. Das Recht der Gesellschaft. Frankfurt am Main: Suhrkamp, 1993. p. 21). ${ }^{9}$ LUHMANN, Niklas. La Sociedad de la Sociedad. México: Editorial Herder, S. de R.L. de C.V, 2006. p. 33. 10 "Quando se quer saber o como é preciso observar o observador". (LUHMANN, Niklas. Das Recht der Gesellschaft. Frankfurt am Main: Suhrkamp, 1993. p. 101).

11 Neste ponto, faz-se preciso consignar que o que aqui esta envolvido não é mais apenas uma autoorganização, no sentido de controle e mudança de estruturas pelo próprio sistema, e assim não mais autonomia no velho sentido de autorregulação. [...] o conceito meramente enuncia que elementos e estruturas de um sistema existem somente à medida que consegue manter sua autopoiese. Ver nesse sentido: LUHMANN, Niklas. Das Recht der Gesellschaft. Frankfurt am Main: Suhrkamp, 1993. p. 60 e ss.

${ }_{12}$ Aqueles, por exemplo, que se destinam a escrever sobre teoria do direito são observadores de primeira ordem, uma vez que estão diretamente ligados a construção da identidade do sistema e sua autodescrição, contudo, aqueles que se perguntam o "como isso se dá" realizam uma observação de segunda ordem. 
que o direito é."13 Neste sentido, o direito é: "uma história sem fim, um sistema autopoiético, que só produz elementos para poder produzir mais elementos."14

Entretanto, tal observação descritiva de caráter recursivo e temporalizado, somente se mostra possível através do estabelecimento de uma distinção primária que, no caso, vem a ser sistema/ambiente ${ }^{15}$. Em outras palavras, mediante uma forma ${ }^{16}$. De fato, o sistema social se constitui e se mostra observável a partir de sua função de apreensão e redução através do sentido ${ }^{17}$, processado como comunicação, da totalidade das expectativas de acontecimentos possíveis de seu ambiente de complexidade. ${ }^{18}$ É assim que este constrói suas fronteiras funcionais-estruturais e tentativas de generalização e vivência das ações, bem como certo controle de contingências. ${ }^{19}$ É tendo em vista estas posições, que nos permitimos explicitar que o conceito de comunicação possui grande relevância na teoria dos sistemas autopoiéticos de Niklas Luhmann, visto que a analítica observadora da sociedade, na qual esta se descreve teoricamente como um sistema social auto-observante e autodescritivo, inclui em si, todos os demais sistemas sociais diferenciados, portanto, toda construção da comunicação. ${ }^{20}$

Em síntese, a comunicação para Luhmann pode ser definida como uma forma peculiar de processar o sentido. Forma, esta, que serve de meio a uma diferenciação na operação sistêmica social. ${ }^{21}$ Dessa maneira, presta-se o conceito de comunicação para a observação de distinções que possibilitam, sem embargo, descrever a estabilização, a constituição e estabilização das operações do sistema social. Consequentemente, a própria comunicação é,

\footnotetext{
13 LUHMANN, Niklas. Das Recht der Gesellschaft. Frankfurt am Main: Suhrkamp, 1993. p. 67.

${ }^{14}$ LUHMANN, Niklas. Das Recht der Gesellschaft. Frankfurt am Main: Suhrkamp, 1993. p. 238.

15 LUHMANN, Niklas. La Sociedad de la Sociedad. México: Editorial Herder, S. de R.L. de C.V, 2006. p.43.

16 "O termo "formas" é usado aqui no sentido de George Spencer Brown, como marcadores para limites que separam dois lados". (LUHMANN, Niklas. Das Recht der Gesellschaft. Frankfurt am Main: Suhrkamp, 1993. p. 35).

17 LUHMANN, Niklas. Sociologia como teoria dos sistemas sociais. In: Pensamento de Niklas Luhmann, col. TA PRAGMATA, org. José Manuel dos Santos, Portugal: Universidade da Beira Interior, 2005. p. 80.

18 LUHMANN, Niklas. Sociologia como teoria dos sistemas sociais. In: Pensamento de Niklas Luhmann, col. TA PRAGMATA, org. José Manuel dos Santos. Portugal: Universidade da Beira Interior, 2005. p. 77.

19 LUHMANN, Niklas. Sociologia como teoria dos sistemas sociais. In: Pensamento de Niklas Luhmann, col. TA PRAGMATA, org. José Manuel dos Santos. Portugal: Universidade da Beira Interior, 2005. p. 81.

20 LUHMANN, Niklas. La Sociedad de la Sociedad. México: Editorial Herder, S. de R.L. de C.V, 2006. pp. $122-129$.

${ }^{21}$ Neste diapasão: LUHMANN, Niklas. Das Recht der Gesellschaft. Frankfurt am Main: Suhrkamp, 1993. pp. 48-49.
} 
nesta perspectiva, uma operação seletiva processadas em três operações circulares: informação, transmissão/mensagem e entendimento. ${ }^{22}$

A informação, trata-se, não obstante, de uma seleção da memória do sistema, constituindo um construto organizativo do qual eventos são selecionadas como sendo relevantes para a continuidade das operações episódicas ou para o esquecimento do sistema. Neste sentido, tem-se que para se operar um ato na comunicação é preciso atribuir ao evento surpresa critérios de rejeição e de não rejeição. Neste diapasão, permitimo-nos explicitar que a informação pode ser descrita como uma referência externa, ao ambiente, por exemplo.

Por outro lado, a transmissão/mensagem tem de ser vista a partir da autorreferência, ou seja, uma mediação entre autorreferência e heterorreferência pela própria autorreferência operativa do sistema. Por fim, o entendimento se refere à condição de possibilidade operativa seguinte em ulteriores comunicações. Assim sendo, a síntese dessas três formas seletivas só pode ser um evento autorreferencial fechado.

Tais questões possibilitam explicitar a construção do que é social, visto que para a pragmática sistêmica luhmanniana o que é social é nada mais que comunicação. Implica, destarte, dizer que o ambiente é então apenas um estímulo e não uma fonte real de informação, em outras palavras, entendimento significa uma rede de eventos comunicativos em um processo de comunicação autorreferencial da sociedade.

Desse modo, a sociedade contemporânea teoricamente descrita e observada a partir de si própria, distingue-se, todavia, daquela sociedade de formação segmentária ou ainda daquela disposta em estratos (observável, sobretudo, no período medieval), no sentido da observação da redução da alta probabilidade dos acontecimentos possíveis de seu ambiente por meio de uma diferenciação interna em sistemas funcionalmente diferenciados. Daí o termo, "sociedade funcionalmente diferenciada".

Estes sistemas, por consequência, promovem suas respectivas funções mediante a um fechamento/autonomia operacional, certo de que processam a comunicação sob o aspecto de um ambiente delimitado de complexidade e se autorreproduzem a partir de seus próprios elementos e, deste modo, são conceituados como autopoiéticos ${ }^{23}$.

Em resumo pode-se dizer que conceito de autopoiese foi trabalhado primeiramente nas ciências biológicas por Humberto e Maturana $^{24}$ e diz respeito, em síntese, à questão da

\footnotetext{
22 LUHMANN, Niklas. Social systems. California: Stanford University, 1995. p.140.

23 LUHMANN, Niklas. La Sociedad de la Sociedad. México: Editorial Herder, S. de R.L. de C.V, 2006. p. 45.

${ }^{24}$ MATURANA, Humberto; VARELA, Francisco. De máquinas e seres vivos: autopoiese: a organização do vivo. 3.ed. Porto Alegre: Artes Médicas, 1997. p. 88.
} 
autorreprodução das células a partir de sua própria recursividade estrutural. Luhmann, ao realizar uma transposição do conceito para as ciências sociais na década de 1980, descreve os sistemas sociais como sendo também autopoiéticos ${ }^{25}$. Sistemas sociais autopoiéticos, para a metodologia pragmática sistêmica, configuram-se como aqueles que possibilitam ser descritos e observados partindo de suas próprias estruturas e elementos recursivos que processam a comunicação da sociedade com base em sua estrutura e operação seletiva, material (isto, ou aquilo), temporal (passado/futuro) e social (alter/ego) do sentido. ${ }^{26}$

Dessa maneira, o direito, na metodologia pragmática luhmanniana, é entendido como um sistema social, de modo que este opera autonomamente e exerce sua função no antro da própria sociedade, construindo, igualmente, sentido a comunicação social de forma autopoiética.

Pode-se definir a autopoiese do direito da sociedade como operações observáveis pelo conjunto de construção de distinções que partem de processos seletivos de autorreferência/heterorreferência, relacionados à sua clausura operativa, reflexão e reflexividade.

Sem embargo, em relação à autorreferência, deve-se explicitar que o sistema, haja vista suas próprias operações, autorreproduz-se sob um construto de sentido seletivo, isto é, uma clausura operativa autônoma que distingue dentre as possibilidades do ambiente e as organiza. Em relação ao sistema do direito, tal operação se mostra observável a partir da adoção histórica de um código sob o esquema direito e não direito ${ }^{27}$. 0 sistema, neste sentido, delimita sua esfera de atuação tendo em vista a sua própria constituição comunicativa de sentido.

Reflexividade, em outro aspecto, relaciona-se à construção observável pelo sistema da possibilidade de fazer referência a procedimentos próprios. No sistema do direito, esta pode ser

\footnotetext{
${ }^{25}$ LUHMANN, Niklas. La Sociedad de la Sociedad. México: Editorial Herder, S. de R.L. de C.V, 2006. p. 44. Com a diferença de Maturana no sentido de colocar a auto-observação como parte da autorreprodução. Em outras palavras, Luhmann coloca a auto-observação como componente necessário à reprodução da autopoiese, diferente de Maturana que, por outro lado, exige para a produção das relações entre sistema e ambiente um observador na qualidade de outro sistema. Para tanto, ver também LUHMANN, Niklas. La Sociedad de la Sociedad. México: Editorial Herder, S. de R.L. de C.V, 2006. p. 100 e ss e LUHMANN, Niklas. Sistemas Sociais: esboço de uma teoria geral. Rio de Janeiro: Vozes, 2016. p. 56 e ss.

${ }^{26}$ LUHMANN, Niklas. La Sociedad de la Sociedad. México: Editorial Herder, S. de R.L. de C.V, 2006. p. 46.

27 Normalmente as traducões brasileiras de recht/unrecht são condessadas nos conceitos licito/ilícito. Contudo, preferimos utilizar os termos direito/não direito, por delinear melhor, não obstante, a perspectiva de luhmanniana da forma estrutural dos sistemas de comunicação de sentido, o que não permite causar a ilusão conceitual de que o sentido da forma do direto estaria ligado a uma dedução lógica da legislação. Ver nesse sentido: LUHMANN, Niklas. Das Recht der Gesellschaft. Frankfurt am Main: Suhrkamp, 1993. p. 574).
} 
descrita quando um procedimento realiza referências ao próprio procedimento, uma maneira de autorreferência processual. ${ }^{28}$

$E$, por fim, os processos de reflexão, que se referem à própria construção da identidade do sistema, podendo, outrossim, proceder autorreferências e heterorreferências autodescritivas $^{29}$. No direito, de acordo com Gunther Teubner ${ }^{30}$ : "trata-se de delimitar as reais operações de produção das normas jurídicas concretas”.

Tais operações, observáveis, sobretudo, sob a égide das noções acima delineadas, permitem-nos enxergar o construtivismo operacional fechado ${ }^{31}$ do sistema social do direito, de maneira que necessitamos ainda explicitar como é que o sistema jurídico se diferencia na comunicação social, isto é, como ele produz sua identidade, tendo em vista sua autorreflexão. É desse modo que pretendemos no próximo capitulo nos debruçarmos sobre a questão da produção da identidade do direito, sobretudo, naquilo que se refere a sua autodescrição sistêmica.

\section{A AUTODESCRIÇÃO NO SISTEMA JURÍDICO}

Como já destacamos, para a pragmática sistêmica Luhmanniana, a comunicação é um processo recursivo genuinamente observável a partir do sistema da sociedade. Assim sendo, “todos os esforços empenhados pelo direito em conhecer e reconhecer se dão na sociedade." 32 . Portanto, a produção comunicativa necessita se fazer compreensível (acoplável à consciência), sobretudo, pelo meio simbólico da linguagem ${ }^{33}$, como sendo direito sob as condições de expectativas sociais de cada caso.

Contudo, a forma da diferenciação funcional da sociedade contemporânea em distintos sistemas comunicativos permite observar tanto descrições externas como internas. Neste interim, por exemplo, a ciência, a partir de suas operações buscando observar e descrever o direito, ou ainda, a política, valendo-se de sua forma de observação, entender o direito como seu instrumento.

28 Nesse sentido, verifica-se que é o próprio processo que delimita as provas a serem produzidas, os prazos e os deveres das partes, por exemplo.

29 LUHMANN, Niklas. La Sociedad de la Sociedad.México: Editorial Herder, S. de R.L. de C.V, 2006. p. 62.

30 TEUBNER, Günther. O direito como sistema autopoiético. Lisboa: Fundação Calouste Gulbekian, 1993. p. 86.

31 LUHMANN, Niklas. Das Recht der Gesellschaft. Frankfurt am Main: Suhrkamp, 1993. p. 56.

32 LUHMANN, Niklas. Das Recht der Gesellschaft. Frankfurt am Main: Suhrkamp, 1993. p. 667.

${ }^{33}$ Ver nesse sentido: LUHMANN, Niklas. La Sociedad de la Sociedad. México: Editorial Herder, S. de R.L. de C.V, 2006. pp. 157-160, bem como: LUHMANN, Niklas. Das Recht der Gesellschaft. Frankfurt am Main: Suhrkamp, 1993. p. 47-49. 
Entretanto, partindo de uma descrição sociológica, como pretendemos realizar, devemos buscar explicitar o sistema observando-o como um sistema provido de conteúdo teórico, ou nas palavras de Luhmann, “como um sistema que se descreve a si mesmo"34. Desse modo é que nossa descrição deve incluir, em especial, as tentativas de esclarecimento teóricojurídico das questões fundamentais do direito, de maneira a realizarmos uma observação da observação, sob pena de nos vermos como própria autodescrição do (no) sistema. Tamanha complexidade e afastamento, exige, de nossa parte, o uso de distinções, a qual nos concentraremos nesse momento na diferença entre o auto-observar e o autodescrever.

De acordo com Luhmann, auto-observação nada mais é do que "a correspondência entre a operação singular, as estruturas e operações do sistema jurídico. [...] A implicação ou explicação de que em uma comunicação se trata do que é lícito ou ilícito."35. Dessa maneira, em outras palavras, a auto-observervação permite a (auto) identificação do sistema na comunicação social.

Por outro lado, autodescrições significam a representação da unidade auto-observada do sistema no próprio sistema. Portanto, não se trata unicamente da recursividade operacional de conexão referenciada por um código, mas de uma reflexão da unidade do sistema no sistema, proporcionadas, sobretudo, pela preparação de textos (teorias, jurisprudência, dogmática...) que devam ser utilizados repetidamente.

Desse modo, a autodescrição permite uma tematização textual autológica, para usar um termo da semântica linguística, do sistema no próprio sistema, isto é, a própria construção da identidade do sistema jurídico. ${ }^{36}$ Impede destacar, por consequência, que as operações de autodescrição do sistema jurídico não consistem, em si, na justificação das decisões tomadas pelo sistema, isto, em outro aporte, cabe à argumentação jurídica, que tem por sentido fixar as redundâncias/conservações decisórias operacionais em relação às variedades possibilitadas pela contingência e simultaneidade cognitiva da sociedade. ${ }^{37}$ "A tarefa especial da autodescrição do sistema jurídico não consiste na justificação da decisão altamente diferenciada, mas na representação da unidade, da função, da autonomia e da indiferença do sistema jurídico"38, de

\footnotetext{
${ }^{34}$ LUHMANN, Niklas. Das Recht der Gesellschaft. Frankfurt am Main: Suhrkamp, 1993. p. 670.

35 LUHMANN, Niklas. Das Recht der Gesellschaft. Frankfurt am Main: Suhrkamp, 1993. p. 669.

36 TEUBNER, Günther. O direito como sistema autopoiético. Lisboa: Fundação Calouste Gulbekian, 1993. p. 86.

37 Ver nesse sentido: LUHMANN, Niklas. Das Recht der Gesellschaft. Frankfurt am Main: Suhrkamp, 1993. p. 451-545.

38 LUHMANN, Niklas. Das Recht der Gesellschaft. Frankfurt am Main: Suhrkamp, 1993. p. 671.
} 
maneira que esta, neste contexto, está mais como um fixador de limites interpretativos do próprio sistema.

Consequentemente, a autodescrição permite uma tematização textual da comunicação de forma autológica ${ }^{39}$, isto é, do sistema no próprio sistema. A própria construção auto-operada (recursiva) da identidade do sistema jurídico. ${ }^{40}$ Neste ponto, importa consignar que, diferente de Teubner e Rocha ${ }^{41}$, por exemplo, preferimos utilizar, com Luhmann, a noção de autodescrição e não de autopoiese propriamente dita, uma vez que nos posicionamos favoráveis ao valor analítico da distinção entre os conceitos de autopoiese, auto-observação reprodução autopoiética e autodescrição. ${ }^{42}$ Tal diferenciação possibilita o observar que a execução de sistemas sociais em sua autorreprodução e em seus paradoxos só pode ser realizada com auxílio de observações das auto-observações e das autodescrições. Contudo, não se intenta dizer aqui que para a observação das autodescrições do sistema é preciso separar reprodução autopoiética de autodescrições e da auto-observação. Como se pode perceber, é somente pelas noções de reprodução autopiética (autodescrições e auto-observação) e de autopoiese que conseguimos colocar a proposta do manejo do paradoxo do sistema também nas autodescrições, e não propriamente dito somente no contexto analítico das auto-observações. ${ }^{43}$

O problema de tal questão, é que a mesma diferença que possibilita a distinção sistêmica, também o realiza, isto é, o identifica, o que gera, não obstante, um paradoxo. 0 paradoxo da renúncia de que em algum momento se deve encontrar a justificação última internamente. "Na realização da autodescrição, é o próprio sistema que deve fazer de si um objeto de pressuposição- e de aceitação" (o direito diz o que é o direito porquê...). ${ }^{44}$

Como já mencionamos, é imprescindível para a autodescrição sistêmica textos em forma escrita, de maneira que foi somente com o auxílio da tipografia que se pode traduzir diferenciações reflexivas adicionais, de início por meio da filosofia, por consequência, da

\footnotetext{
${ }^{39}$ Neste sentido: WITTGENSTEIN, Ludwig. Tractus logico-philosofico. São Paulo: Editora da Universidade de São Paulo, 1988. Disponível em: https://marcosfabionuva.files.wordpress.com/2011/08/tractatuslogico-philosophicus.pdf. Acesso em: 12 maio 2017.

40 TEUBNER, Günther. 0 direito como sistema autopoiético. Lisboa: Fundação Calouste Gulbekian, 1993. p. 86.

${ }^{41}$ ROCHA, Leonel Severo. Paradoxos da Auto-observação: percursos da teoria jurídica contemporânea. Curitiba: JM, 1977.

42 Nas palavras de Luhmann: "A autopoiese ocorre ou não ocorre- assim como um sistema biológico vive ou não vive. A autodescrição, ao contrário, é um processo capaz de articular e modificar a si mesmo, desenvolvendo uma semântica que permite ao sistema operar". (LUHMANN, Niklas. Sistemas Sociais: esboço de uma teoria geral. Rio de Janeiro: Vozes, 2016. p. 299).

${ }^{43}$ Neste sentido, ver: LUHMANN, Niklas. Sistemas Sociais: esboço de uma teoria geral. Rio de Janeiro: Vozes, 2016. p. 192 e ss.

${ }^{44}$ LUHMANN, Niklas. Das Recht der Gesellschaft. Frankfurt am Main: Suhrkamp, 1993. p. 673.
} 
filosofia do direito. "A operação da autodescrição é, portanto, publicação impressa [...] A autodescrição tem, ela própria, de ordenar o sistema que ela descreve, e isso só pode ocorrer quando adotados e tematizados os vínculos específicos do sistema." 45

Neste sentido, a autodescrição do sistema tem sempre de partir do pressuposto que o sistema jurídico se encontra relacionado a uma comunicação controversa. Portanto, há uma necessidade de estilização da decisão sobre um caso concreto que, não obstante, tem de respeitar a necessidade de chegar a uma decisão no centro do sistema, na jurisdição. Assim sendo, a autodescrição tem de dar conta também de tal estilização de controvérsias. ${ }^{46}$

Entretanto, de modo diferente à necessidade de decisão pelo sistema, bem como a sua consequente justificação, a autodescrição do sistema pode dispor da questão de se colocar em algum discurso dogmático. Não é questão para ela, por exemplo, a responsabilidade do fornecedor pelos produtos defeituosos e dos danos. A esta compete tão somente esclarecer o que está implícito quando um sistema antevê uma reposta a todas as perguntas, "de maneira que os meios de argumentação pode mudar, mas coação à decisão permanece [...] É preciso descrever o sistema de modo que a busca pela resposta certa continue provida de sentido, mesmo que exista uma dúvida cada vez maior quando à existência de uma resposta certa." 47

É desse modo que tais descrições se permitem/permitiram recorrer a um ponto externo do sistema jurídico tornando problematizável internamente, como a natureza e a religião no medievo, por exemplo, ou ainda, como dizia Jeremy Bentham ${ }^{48}$, já no século XIX, à autoridade soberana do legislador político como fonte do direito. É nesse sentido também que Hans Kelsen propõe em sua Teoria Pura do Direito buscar formular o problema a partir de conhecimento jurídico autônomo, tentando resolvê-lo, sobretudo, no estilo cientifico de colocações de hipóteses propositivas. ${ }^{49}$ Tais colocações, orientadas, em especial, por colocações metodológicas cientificas, têm sido chamadas nas últimas décadas como "Teorias Jurídicas". 50

\footnotetext{
45 LUHMANN, Niklas. Das Recht der Gesellschaft. Frankfurt am Main: Suhrkamp, 1993. p. 674.

${ }^{46}$ Diz Luhmann: Independentemente de ser o que se busca: é preciso justificá-lo no sistema, recorrendose aos meios de argumentação do sistema. Isso não depende necessariamente de haver para toda pergunta, em última instância, uma resposta correta; no entanto, é preciso se comunicar como se a houvesse, et Deus non daretur (ainda que Deus não se apresentasse). (LUHMANN, Niklas. Das Recht der Gesellschaft. Frankfurt am Main: Suhrkamp, 1993. p. 677).

47 LUHMANN, Niklas. Das Recht der Gesellschaft. Frankfurt am Main: Suhrkamp, 1993. p. 678.

${ }^{48}$ Neste sentido: POSTEMA, J.Gerald. Bentham and the common law tradition. Oxford: Clarendon pass, Oxford Unisity press, $1986 . \quad$ Disponivel em: https://www.jstor.org/stable/2380941?seq=1\#page_scan_tab_contents. Acesso em: 8 maio 2017. ${ }^{49}$ Ver nesse sentido: KELSEN, Hans. Teoria Pura do Direito. 6. ed. São Paulo: Martins Fontes, 1998. p. 50 e ss.

${ }^{50}$ LUHMANN, Niklas. Das Recht der Gesellschaft. Frankfurt am Main: Suhrkamp, 1993. p. 678
} 
Valendo-se de aparatos de abordagens interdisciplinares cientificas, tais como: a hermenêutica $^{51}$, ou a sociologia ${ }^{52}$, a autodescrição reflexiva do sistema jurídico encontrou apoio à possibilidade de ampliação das controvérsias e a precondição para possibilidade de decidi-las. “Todas tentativas fazem uso de argumentos plausíveis, postos à disposição pela sociedade moderna, funcionalmente diferenciada, qual seja, a recorrência a outro sistema de funcionamento." 53

Todavia, tais disposições conduzem a problemática de como decidir entre essas “diferentes opções” como opções do próprio sistema jurídico (um paradoxo, portanto). Neste sentido, é precisamente esse problema que podemos desdobrar com a identificação das operações de auto-observação e autodescrição, de modo que se quisermos saber como o sistema se autodescreve, faz-se preciso observar as diferentes teorias que buscam a identidade reflexiva do sistema no próprio sistema, o que, por conseguinte, inclui ter de renunciar a uma solução unitária, e se atentar pelo modo como o qual o sistema limita sua validade e seus meios de argumentação. ${ }^{54}$

Desse modo, diz Luhmann:

A autodescrição do sistema tem de se identificar com suas condições, para as quais tem de haver acordo ao se buscar as soluções do problema no sistema. Isso torna tolerável para nós aceitar que tenhamos de viver com um open texture, e que muitas controvérsias não possam ser decididas pela via da argumentação. 0 decisivo aqui é que o próprio sistema limita a margem de manobra à qual é preciso recorrer em suas normas de competências, e de modo puramente factual procede-se a disposições sobre os símbolos de validade que então, por sua vez, oferecerão pontos de partida para outras operações. A referência à unidade do sistema é substituída pela referência ao fechamento do sistema. ${ }^{55}$

${ }^{51}$ No Brasil atualmente, com forte representação do professor Lenio Luiz Streck.

52 Sobretudo as perspectivas dos conceitos trabalhados nos Estados Unidos de social engineering, social policy, legal realism, proteção de interesses e afins. Ver nesse sentido: POUND, Roscoe. Mechanical Jurisprudence. Columbia Law Review, 1908. pp. 605-623. SUMMERS, Robert Samuel. Instrumentalism and American Legal Theory. Ithaca, N.Y: Cornell University Press, 1982, "na visão proteção dos interesses sociais justos", bem como ainda, LUHMANN, Niklas. Das Recht der Gesellschaft. Frankfurt am Main: Suhrkamp, 1993. pp. 519-524, na discussão sobre conceito e interesses, autorreferência e heterorreferência.

${ }^{53}$ LUHMANN, Niklas. Das Recht der Gesellschaft. Frankfurt am Main: Suhrkamp, 1993. p. 679.

${ }^{54}$ Ver nesse sentido o que faz as teorias contemporâneas institucionais do direito em: MACCORMICK, Neil. Grundlagen des institutionalistischen Rechtpositivismus. Berlim: Duncker \& Humblot Gmbh, 1985.

${ }^{55}$ No original: Selbstbeschreibung des Systems sich mit den Bedingungen identifizieren muß, aufdie man sich einlassen muß, wenn man im System Problemlösungen sucht. Das macht es erträglich zu akzeptieren, daß man mit einem »open texture « zu leben hat und manche Kontroversen nicht argumentativ zu entscheiden sind. Entscheidend ist, daß das System selbst den Spielraum einschränkt, in dem es auf reine Kompetenznormen rekurrieren muß und rein faktisch über Geltungssymbole disponiert, die dann ihrerseits Ausgangspunkte für weitere Operationen bieten. An die Stelle der Berufung auf Einheit tritt die Berufung auf Geschlossenheit des Systems. LUHMANN, Niklas. Das Recht der Gesellschaft. Frankfurt am Main: Suhrkamp, 1993. pp. 506-507. 
Neste interim, ao realizar uma observação das teorias contemporâneas, tais como: a análise econômica do direito, principiológica, ou ainda de um direito positivo ${ }^{56}$, tem-se que o direito só se põe ao debate na medida em que se encontra conformado e aceito. Desse modo, o processo de positivação do direito, já no início no século XIX, principalmente sobre influência da filosofia empirista de David $\mathrm{Hume}^{57}$, encontra-se intrinsicamente relacionado às mudanças estruturais que pretendem adaptar a sociedade a um maior grau de individualidade dos indivíduos, renunciando, outrossim, a racionalidade normativa abrangente (subjetiva) ou cosmológica (natural) que tanto marcou as pretensões auto descritivas do direito natural.

Contudo, importante se faz destacar que é precisamente o conceito de direito natural, que acompanhou o surgimento da ordenação jurídica medieval, a transição para o Estado territorial moderno, para o absolutismo, para o absolutismo esclarecido e, por último, para o processo jurídico constitucional de positivação dos direitos humanos, que se comprovou capaz de adaptação. ${ }^{58}$

Assim sendo, abstraindo de sua obsolescência semântica, uma vez que atualmente se não se encontram fundamentos sócio-estrurais que em determinado momento pareceram tornar possível acoplamentos entre direito natural, bem comum e justiça ${ }^{59}$, a positividade do direito, de acordo com Luhmann, converte-se no topo da auto representação e crítica na (da) sociedade moderna, "uma vez que o positivo não é natural, mas algo dado e que depois, como decisão, deve ser observado. $O$ positivo não é especulativo, mas algo que se encontra demonstrativamente fundamentado em fatos e leis." 60

Eis, portanto, o "segredo contextualizado" do êxito do positivismo nos séculos XIX e XX. 0 positivismo jurídico se fecha construtivamente e operacionalmente na perspectiva auto descritiva do sistema, podendo constantemente ser modificado, certo de que em caso de dúvida a reflexividade social contemporânea remete não ao consenso, mas ao dissenso. "A teoria do direito da sociedade moderna, em seu lugar, oferece dois modelos distintos de autodescrição [...] cada uma das partes dessa controvérsia, orienta-se pelos defeitos da outra parte, mas não pelos seus próprios." ${ }^{61}$ Assim, na contemporaneidade, visto a derrocada dos fundamentos

\footnotetext{
${ }^{56}$ LUHMANN, Niklas. Das Recht der Gesellschaft. Frankfurt am Main: Suhrkamp, 1993, p. 693.

${ }^{57}$ LUHMANN, Niklas. Das Recht der Gesellschaft. Frankfurt am Main: Suhrkamp, 1993, p. 690.

${ }^{58}$ LUHMANN, Niklas. Das Recht der Gesellschaft. Frankfurt am Main: Suhrkamp, 1993, p. 697.

59 Ainda que se observem esforços para os manterem e retificá-los em: "HOFFE, Otfried. Politische Gerechtigkeit: Grundlegung einer kritischen Philosophie von Recht und Staat. Frankfurt am Main: Suhrkamp, 1987.

60 LUHMANN, Niklas. Das Recht der Gesellschaft. Frankfurt am Main: Suhrkamp, 1993, p. 695.

${ }^{61}$ LUHMANN, Niklas. Das Recht der Gesellschaft. Frankfurt am Main: Suhrkamp, 1993, p. 699.
} 
cosmológicos/generalistas do direito natural e suas autorreflexões, o partido dos princípios expõe a autodescrição normativa do sistema jurídico em relação ao próprios meios argumentativos do sistema, de modo que para estes existem, de fato, algo como boas e más razões, princípios últimos como obrigatórios no sistema. Neste sentido é que se encontram autores como: Ronald Dworkin com sua tese da resposta única e princípios da comunidade política $^{62}$, bem como, no Brasil, o professor Lênio Luiz Streck, com sua tese da resposta Constitucionalmente adequada ${ }^{63}$ como uma tradição jurídica autêntica, de maneira que quem os procura negar "será caracterizado como: destrutivo, niilista, anarquista, decisionista, oportunista, positivista". ${ }^{64}$

Por outro lado, o partido positivista e suas atuais releituras, como ressalta Luhmann ${ }^{65}$, considera tais afirmações uma simples manobra de desvio de atenção dos adeptos da antiga cosmologia. Os adeptos dos princípios não têm capacidade de reação ante a realização da difícil função unificadora de um princípio, ante a não concretização lógica (sem contradições) no sistema. Assim, encontra dificuldade em proporcionar uma resposta pronta/concreta para o problema de como identificar a existência de um princípio/solução para um caso difícil. Por outro lado, o positivista diz a ter, ao se referenciar pelo direito valido/vigente, no símbolo de validade circulante no próprio sistema fechado (fontes do direito) e no que se convencionou chamar atualmente de ponderação de princípios.

A teoria dos princípios e a teoria positivista (e suas atuais releituras), se estivermos certos em nossas leituras, permitem-se se identificar como autodescrições do sistema jurídico pelo fato de se comprometerem com o sistema, de maneira, a ditar, uma pratica normativa do direito. Contudo, as diferenças entre elas não podem ser sobrepostas, uma vez que se trata de uma diferença entre diferentes concepções de princípios e validade circulante interna, de modo que nenhuma destas abordagens auto descritivas conquistou, como, de certa maneira, o positivismo do século XIX, uma unicidade do sistema no sistema, de maneira que "validade e raciocínio justificador não podem ser reconciliados, e, portanto, é preciso optar por uma versão ou por outra." 66

Dessa maneira, as condições atuais da autodescrição do sistema permitem serem observadas a partir da diferenciação de um sistema de funcionamento fechado em si e

62 DWORKIN, Ronald. Taking Rights Seriously. Cambridge Mass, 1988; DOWRKIN, Ronald. The Law's Empire. Cambridge Mass, 1986.

${ }^{63}$ Ver, sobretudo, STRECK, Lenio Luiz. Verdade e Consenso. 5. Ed. São Paulo: Saraiva, 2014.

64 LUHMANN, Niklas. Das Recht der Gesellschaft. Frankfurt am Main: Suhrkamp, 1993. p. 702.

${ }^{65}$ LUHMANN, Niklas. Das Recht der Gesellschaft. Frankfurt am Main: Suhrkamp, 1993. p. 703.

${ }^{66}$ LUHMANN, Niklas. Das Recht der Gesellschaft. Frankfurt am Main: Suhrkamp, 1993. p. 713. 
operativamente dependente de si, bem como a partir de uma construção contínua de uma observação de segunda ordem no sistema. "Uma vez que o sistema é fechado, ele tem de submeter todas as suas operações, com cujas questões jurídicas é constituído e observado, a suas próprias observações" ${ }^{\circ 7}$, e é justamente em virtude desse fato, que pretendemos sugerir que leitura feita de corrupção sistêmica, que guarda uma certa correlação com a crítica ao ativismo judicial, uma vez que ambas se referem a preceitos autorreflexivos normativos, encontram-se observáveis como construtos argumentativos autodescritivos de um dos partidos explicitados a fim de promover a sua identidade teórica à autodescrição do sistema jurídico, facilitando e, ao mesmo tempo, dificultando as críticas. Portanto, visam alcançarem a possibilidade de decisão, tornando, por conseguinte, invisível os seus paradoxos teóricos e explicitando a função autodescritiva da reprodução autopoiética do direito. Em outras palavras, o sentido de corrupção sistêmica e de ativismo judicial são construções de observadores na autodescrição do sistema.

Assim, no próximo capitulo, já não mais nos perguntaremos sobre o que é princípio, ou melhor, sobre o que dizem de corrupção, ou ainda, o que deve valer como direito positivo em relação à corrupção? Qual a melhor teoria? Normatividades não nos interessam como observadores dos observadores, contudo, faremos os seguintes questionamentos, como faz o sistema? Como se encadeia a operação sob a irritação duradoura pelo ambiente? Qual a função e a condição de possibilidade do invisibilizar do paradoxo na autodescrição?

\section{A CORRUPÇÃO SISTÊMICA E O ATIVISMO JUDICIAL NA AUTODESCRIÇÃO SISTÊMICA}

Os conceitos de corrupção sistêmica, bem como o de altopoiese do direito no Brasil, encontram-se, para elencar alguns autores, atualmente trabalhados a partir dos escritos de Marcelo Neves, Orlando Villas-Boas Filho e Artur Stamford da Silva. Neste sentido, para supor a ocorrência de déficits de diferenciação funcional em países de modernidade periférica, como o Brasil, o argumento de Neves pressupõe uma concepção normativa de autopoiese. Isto é, a linha intelectiva prescreve uma realidade que deveria ser, e condena uma realidade que é. Desse modo, releitura se dá no sentido de que em certas regiões do mundo não se revela possível observar que a hipercomplexificação social seguiu a construção de sistemas sociais complexos dotados e estruturados tendo por base operações autônomas. Dessa noção, é que se parte a

${ }^{67}$ LUHMANN, Niklas. Das Recht der Gesellschaft. Frankfurt am Main: Suhrkamp, 1993. p. 716. 
distinção normativa entre modernidade periférica e modernidade central. A primeira, sem embargo, refere-se a um contexto observável de déficit dos preceitos da diferenciação funcional, por consequência, constituindo-se em uma modernidade negativa. Entretanto, de modo diferente da primeira, na segunda forma se revela possível observar a diferenciação funcional autopoiética, especialmente, no que se refere à substituição progressiva dos estratos sociais pela distinção autônoma funcional dos sistemas sociais. ${ }^{68}$

Por consequência, a dita modernidade periférica se mostra observável não só pelo fato da não diferenciação funcional, mas também pela produção de uma complexidade própria, onde não se pode defini-la, nem como seguidora dos preceitos estratificados, tampouco com os de diferenciação funcional. Dessa maneira é que Neves, ao observar a experiência jurídicopolítica realizada no Brasil, a enquadra nas noções de modernidade periférica, uma vez que não se mostra possível observar a autonomia do direito e a deficiente realização consequente do Estado de Direito no Brasil.

Dirá que, ao invés de autopoiese do direito, caberia falar em alopoiese do direito, visto que as sobreposições particularistas dos códigos político e econômico às questões jurídicas impossibilitam a construção da identidade do sistema jurídico. 0 que se observa, por consequência, é uma corrupção sistêmica, de modo que o sistema jurídico brasileiro não opera a partir de seu próprio construtivismo operacional, mas com distinções que não o constitui, a exemplo, do poder e não poder, relacionados à racionalidade da política e escassez/não escassez, relacionados à racionalidade econômica. ${ }^{69}$

Em outro aporte, contudo, seguindo o preceito normativo de corrupção, têm-se também os escritos de Artur Stamford da Silva. 0 argumento deste, em síntese, parte da noção de que o direito brasileiro comunica uma dependência da política e da economia em seu funcionamento, sobretudo, no que se refere às influências destes sistemas nas decisões jurídicas. Todavia, para o autor, não serve a noção de corrupção sistêmica para negar a autopoeiese do direito, mas para possibilitar uma verificação de que os limites do direito estão intimamente ligados aos interesses econômicos e políticos em suas operações. Assim, “[...] se a expectativa do brasileiro é que o direito não reage às influências econômicas e/ou políticas, significa que o direito brasileiro

${ }^{68}$ NEVES, Marcelo. Luhmann, Habermas e o estado de direito. Lua nova: Revista Cultura e Política, $\mathrm{n}^{\circ} 37$, 1996. p. 98-99. Disponível em: http://www.scielo.br/pdf/ln/n37/a06n37.pdf Acesso em: 31 jul. 2017. ${ }^{69}$ NEVES, Marcelo. A constitucionalização simbólica. São Paulo: Martins Fontes, 2007. p. 140 e ss. 
comunica essa dependência, ou seja, o acoplamento estrutural do direito da sociedade brasileira com a política e a economia". ${ }^{70}$

Destarte, Orlando Villas-Boas Filho, também com elementos teóricos distintos de Neves, procura explicitar o conceito de modernidade periférica como sendo dotado de aplicações teleológicas, normativas e generalizadoras. ${ }^{71}$ Dessa maneira, para este, deve-se considerar as especificidades regionais para se construir uma teoria observadora do direito brasileiro. Portanto, coloca em pauta uma profícua discussão em relação à necessidade de uma "redução da escala de análise" que, no caso, leve em conta especificidades regionais. ${ }^{72}$

Não obstante a essas pertinentes discussões, fixaremos nossas observações no contexto de um observador das operações do sistema. Consequentemente, se estivermos certos quanto às análises dos autores colocados, tanto os trabalhos de Neves, Villas-Boas Filho e da Silva, como de qualquer outro autor que procure autorrefletir uma identidade ao conceito de corrupção no (para o) sistema do direito, encontram-se na própria autodescrição do sistema, vez que intentam, na qualidade de observadores, manejar/inivisibilizar os paradoxos da autopoiese do sistema, sobretudo, ao procurar tematizar reflexivamente um sentido para a chamada “corrupção". O sentido da “corrupção sistêmica”, em nosso entendimento, encontra-se, portanto, na autodescrição do sistema.

Por outro lado, mas de maneira também autodescritiva, é construída a crítica do ativismo judicial no Brasil, tendo como representante atual, em especial, o jurista Lenio Luiz Streck. Adotando as linhas intelectivas da hermenêutica filosófica, visando, ademais, desvelar uma limitação à discricionariedade das decisões judiciais a partir da tradição histórico-jurídica da comunidade política, adota como marco para tanto a Constituição Federal da República de 1988, com o intuito de propor uma resposta constitucionalmente adequada para casos concretos.

Destarte, no século $X X$, após aquilo que se convencionou denominar de virada linguística (linguistic turn) com Wittgenstein e seu Tratado Lógico Filosófico e Investigações filosóficas ${ }^{73}$,

\footnotetext{
70 SILVA, Artur Stamford da. Decisão jurídica e mudança social. Para uma sociologia da decisão jurídica. confluências- Revista Interdisciplinar de Sociologia e Direito, v. 11, n. 1, p. 143, 2010. Disponível em: http://www.confluencias.uff.br/index.php/confluencias/article/view/177/21 . Acesso em: 15 abr. 2019. 71 VILLAS-BÔAS FILHO, Orlando. Teoria dos sistemas e o direito brasileiro. São Paulo: Saraiva, 2009. pp. 340-383.

${ }^{72}$ VILLAS- BÔAS FILHO, Orlando. Teoria dos sistemas e o direito brasileiro. São Paulo: Saraiva, 2009. pp. 375 e ss.

$73 \mathrm{Na}$ filosofia, costuma-se dividir o pensamento de Wittgenstein em duas colocações. O primeiro Wittgenstein quando se fala no Tratado Lógico Filosófico, bem como em suas concepções de estabelecer as condições lógicas aproximativas do pensamento e da linguagem no sentido de representar analiticamente o mundo. O segundo Wittgenstein, a partir de sua obra: Investigações filosóficas e na sua posição de que a linguagem é parte de uma atividade ou de uma forma de vida. A linguagem, portanto, no
} 
bem como também com a virada ontológica fundamental, a partir de Heidegger e seu Ser e Tempo $^{74}$, concebe-se um novo paradigma filosófico de análise do sentido, agora não mais voltado para a distinção até então prevalente entre sujeito e objeto, mas para uma correlação fenomenológica intersubjetiva, isto é, o sentido passa a ser entendido como produção exógena, para além das fronteiras da consciência transcendental individual. Com Heidegger e a hermenêutica filosófica, pergunta-se pelo sentido tendo em vista o Ser-Ai (Dasein), o ser-nomundo, dotado de historicidade, tempo e temporalidade. Com Wittgenstein, por outro lado, pergunta-se pelo sentido a partir da linguagem. Assim sendo, o sentido/realidade das coisas não é providenciado por uma construção consciente à priori do sujeito, ou pelo próprio objeto, mas intersubjetivamente, na tradição de histórica de uma comunidade, das partes ao todo, e do todo às partes, para falar conjuntamente com Heidegger e sua forma investigativa fenomenológica hermenêutica ${ }^{75}$.

É tendo por base tais acepções que aqueles que procuram analisar as teorias da decisão jurídica tendo em vista a hermenêutica filosófica, em especial, a partir de Heidegger e Gadamer, propõem a delimitação da discricionariedade das decisões judiciais, tão bem explicitada por Hans Kelsen no clássico capítulo VIII da Teoria Pura do Direito, com fulcro na noção de princípios que, definidos como distintos das regras, representam a institucionalização do mundo concreto no âmbito do direito. Dessa maneira, os princípios não estão propriamente ditos nos textos legais (o que não impede, todavia, de serem representados nestes) a possibilitarem subsunções abstrato-fáticas, mas se encontram na própria tradição históricojurídica de uma comunidade política.

Portanto, a crítica do professor Streck direciona-se, sobretudo, a decisões proferidas desprovidas de fundamentação de cunho jurídico e dotada de subjetivismos interpretativos, de modo a prescrever o direito a partir de uma noção principiológica autêntica. Embora o professor Streck não fale explicitamente em corrupção sistêmica, em recente artigo opinativo publicado

segundo Wittgenstein, deixa de se verificar como modo para informações e se converte em uma atividade social de representação do mundo. Neste sentido ver: WITTGENSTEIN, Ludwig. Investigações filosóficas. São Paulo: Nova Cultural, 1999. p. 43 e ss. Disponível em: https://aprender.ead.unb.br/pluginfile.php/170846/mod_resource/content/1/investigac3a7c3b5esfilosc3b3ficas.pdf . Acesso em: 11 maio 2017.

${ }^{74}$ Ver neste sentido: HEIDEGGER, Martin. Sein und Zeit. Tübingen: M. Niemeyer, 1986. p.54.

75 HEIDEGGER, Martin. Sein und Zeit. Tübingen: M. Niemeyer, 1986, §7. Dito de outra maneira, a questão do ser do Dasein é investigada sob a égide da máxima da fenomenologia, do "ir às coisas elas mesmas" [zu den Sachen selbst], quanto com a máxima da "interpretação no horizonte da compreensão", proposta, sobretudo, pela hermenêutica. 
na revista Conjur, em que este faz uma alusão de seus ditames com juristas famosos, como: Hart e Kelsen, este relata:

[...] 9. Luhmann também não se interessa por decisões concretas. Mas, atendendo a insistentes convites, resolveu dizer o que sua teoria sistêmica poderia ajudar na resposta acerca do acerto ou não da decisão. "Há uma programação (legal-constitucional) que o sistema minimamente deve seguir. Se o operador do sistema (juiz, tribunal) não a segue, perde não só a legitimidade, mas a legitimação para agir. 0 sistema do Direito, no seu proceder autopoiético, não encontra estruturas suficientes para uma comunicação que seja divergente àquela exposta pelo artigo 489 , parágrafo $1^{\circ}$ do CPC. Do contrário, haveria uma corrupção sistêmica, uma vez que a resposta jurídica seria o resultado de estruturas diversas ao seu próprio sistema operativo. 0 julgado contrariou a programação legal-constitucional. ${ }^{76}$

Consequentemente, sem embargo, as pretensões críticas do ativismo judicial condizem com a leitura feita sobre a corrupção sistêmica, em especial, pelo seu orientar normativo e autodescritivo.

Não obstante a estas profícuas anotações, o caráter aberto da questão polêmica (o que é o direito?) entre os dois partidos de autodescrição elencados, permitem compreender tautologia destas razões, de modo que, em si próprias, se justifiquem como razoáveis por pertencerem ao construtivismo operacional do sistema jurídico. Para ilustrar: uma relação entre o que o direito é (Streck) e o que o direito não é (Neves).

Neste sentido, a observação de segunda ordem que nos propomos a fazer, tem sempre de partir a existência de uma distinção que, no caso, se dá pela diferença já mencionada entre sistema e ambiente auto-operada. Esta forma de observação permite perceber os paradoxos das observações do sistema, isto é, como ela oculta a multiplicidade das várias possiblidades possíveis (contingência) e a não permissibilidade do outro lado da resposta. Por exemplo, o que distingue princípio de regras é uma regra ou um princípio?

Dessa maneira, observa-se que as noções normativas da concepção de corrupção sistêmica do direito e as críticas do ativismo judicial partem de um esquema de sentido que, desde os tempos gregos, com o mundo das formas de Platão, no telos aristotélico, no medievo com as aequitas ${ }^{77}$, na lição moderna normativa de natureza de "que os homens conhecem seus

\footnotetext{
76 STRECK, Lenio Luiz. Um encontro de titãs: Kelsen, Hart \& Cia analisam acórdão do STJ. Revista Consultor Jurídico, 2016. Disponível em: http://www.conjur.com.br/2016-jul-07/senso-incomumencontro-titas-kelsen-hart-cia-analisam-acordao-stj. Acesso em: 20 fev. 2017.

$77 \mathrm{Na}$ Summa Theologiae de São Tomás de Aquino se lê: Unde omnis lex humanitus posita intantum habet de ratione legis, inqunatum a lege naturae derivatur. Si vero in aliquo, a lege naturali discordet, iam non erit lex sed legis corruptio. (Donde toda lei humanamente assentada tanto tem razão de lei quanto é
} 
direitos naturais ao se unir tendo vista a conformação da sociedade civil”78, implica em uma descrição tendo em vista um critério normativo do desejável e indesejável, do perfeito e do corrupto, de modo que as teorias reflexivas atuais aqui apresentadas, claramente, em suas concepções normativas, carregam e reproduzem essa noção de uma realidade do direito corrupta, de uma tentativa de pôr o direito desejável a partir da autorreflexão.

Portanto, os conceitos de corrupção sistêmica e de ativismo judicial, ao se valerem de tais prescrições normativas, permitem tornar invisível o paradoxo do contingente construtivismo autodescritivo contemporâneo do sistema do direito. Isto é, possibilitam um desdobramento, sob condições intelectivas externas, da unidade e identidade (interna) na própria unidade sistêmica. Em outras palavras, uma descrição interna, como se fosse de índole externa e pudesse proporcionar informação sobre conteúdos objetivos e elidir contradições.

Tais assertivas, de modo algum, reduzem-se a “chover no molhado", ou explicitar a “importância da água para navegação”, mas procuraram ressaltar que a observação da função da invisiblização do paradoxo do direito sob as perspectivas semânticas do ativismo judicial e da corrupção sistêmica possibilitam uma releitura com forças a explicitar o construtivismo atual autodescritivo do sistema social do direito. Autorizam-se, neste sentido, descrever as relações entre os sistemas sociais autônomos em sua busca constante pelo provimento seletivo de sentido à comunicação social, bem como a comprovação de seu dinamismo autopoiético autodescritivo, sobretudo, em ter de incluir/excluir, para continuidade de suas operações, experiências cognitivas históricas da semântica social.

Assim, o sistema jurídico na atualidade produz uma maioria de autodescrições e suscita assim problemas de inconsistência aos quais já não se podem acordar as diferentes correntes debatedoras, mas sim buscar competir para chegar à teoria e a decisão. 0 direito, em outras palavras, a todo o momento se provoca para se permitir esconder de si mesmo.

\section{CONCLUSÃO}

Tal análise, mostra-se importante consignar, não tem a pretensão de ser compreendida como uma desconstrução dos conceitos utilizados pelas teorias até aqui referidas. Contudo, pretende-se destacar com o presente artigo é que toda pergunta pela unidade de uma distinção,

derivada da lei da natureza. Com efeito, se em algo destoe da lei natural, já não será lei, mas corrupção da (ei). Ver nesse sentido: LUHMANN, Niklas. Das Recht der Gesellschaft. Frankfurt am Main: Suhrkamp, 1993. p. 682-699.

78 LUHMANN, Niklas. Das Recht der Gesellschaft. Frankfurt am Main: Suhrkamp, 1993. p. 685. 
portanto, toda a tentativa de observar a forma de observação de observadores, conduz, não obstante, a um paradoxo, a uma oscilação entre interno/externo, igual/desigual, direito/não direito que, nem conforma uma memória, nem geram complexidade estrutural, nem podem garantir uma capacidade de enlace. Em outras palavras, assim o sistema jurídico não pode operar.

Dessa maneira, o que se buscou retratar é como o sistema tem de lidar com aquilo que ele teve de manter latente. Os textos, só são levados em conta quando tem vigência. Figuras de fundamentação tem uma clara base dogmática. Para o sistema fica evidente, neste sentido, que a distinção entre direito e não direito é direito. Da mesma forma, as teorias jurídicas que se restringem à observação interior e à autodescrição, podem prescindir da análise autológica e paradoxal de seus conceitos, mas desse modo prescindem também do entendimento do construtivismo operativo com que o próprio sistema jurídico constrói o seu mundo, o que, por consequência, promove um farto possibilitar de uma observação sociológica jurídica.

Partindo deste preceito, na posição de um observador da auto-observação e da autodescrição do sistema, é que sugerimos com o presente artigo, a representação das formas de dissolução dos paradoxos na autodescrição do sistema, uma vez que pela noção de corrupção sistêmica e ativismo judicial, explicitados como conceitos funcionais autodescritivos, revelam-se sua utilização no sistema jurídico como pontos nos quais se dá a ver a capacidade de adaptação histórica do sistema em sua tentativa de construção de semânticas.

De fato, permitimo-nos constatar principalmente que tais teorias não levam em conta a provável improbabilidade provocada pela autorreferência. Consequentemente, em nossa perspectiva de análise, a construção de sentido para a corrupção, bem como ao ativismo judicial, realiza-se como uma estratégia na autodescrição sistêmica. Se estivermos corretos em nossas colocações, tais autores estão constantemente (como observadores, diga-se) tentando lidar com o operacionalizar criativo do paradoxo do direito em busca de outras formas de observação igualmente contingentes na autodescrição do sistema.

$\mathrm{Na}$ posição de um observador de observações, não importa a teoria que se venha a preferir como autodescrição do sistema jurídico, de modo que há uma condição impossível de se evitar, a de que o sistema não pode prever posições que, sem levar em conta as condições do sistema, tenham razão ou às quais se conceda sempre razão. Explicita-se, portanto, a condição de possibilidade e a função contingencial dos conceitos de corrupção sistêmica e ativismo judicial como uma tentativa contemporânea de manejo do paradoxo do direito na autodescrição do sistema e, consequentemente, da própria manutenção da continuação da comunicação 
jurídica. Entretanto, mesmo que não se descarte a possibilidade de haver direitos especiais, direitos de emergência, direitos condicionados, queremos reforçar e explicitar com tal análise que a autonomia operacional do sistema não pode ser confundida com arbitrariedade, de maneira que esta contém uma limitação a um direito incondicionado de autoexceção que força o sistema a submeter à a autoespecificação histórica. Em outras palavras, há uma tentativa de constantemente se produzir um sentido atualizado e possível para o direito frente à simultaneidade da comunicação da sociedade moderna.

\section{REFERÊNCIAS}

CORSI, Giancarlo. Levando o indivíduo a sério: a relação indivíduo-sociedade na teoria dos sistemas. Tempo soc., São Paulo, v. 27, n. 2, p. 181-198, 2015 . Disponível em:

http://www.scielo.br/scielo.php?script=sci arttext\&pid=S0103-20702015000200181\&lang=pt. Acesso em: 20 maio 2019. doi: http://dx.doi.org/10.1590/0103-2070201529.

DWORKIN, Ronald. Taking Rights Seriously. Cambridge Mass, 1988.

DWORKIN, Ronald. The Law's Empire. Cambridge Mass, 1986.

GLASERSFELD, Von Ernest. Aspects of constructivism: Vico, Berkeley, Piaget. In: M. Larochelle (Ed.), Key works in radical constructivism. Sense Publishers, 2009.

HABERMAS, Jürgen. Teoria do Agir Comunicativo. São Paulo: Martins Fontes, 2012. vol. 02.

HEIDEGGER, Martin. Sein und Zeit. Tübingen: M. Niemeyer, 1986.

HOFFE, Otfried. Politische Gerechtigkeit: Grundlegung einer kritischen Philosophie von Recht und Staat. Suhrkamp: Frankfurt am Main, 2002.

KELSEN, Hans. Teoria Pura do Direito. 6. ed. São Paulo: Martins Fontes, 1998.

LUHMANN, Niklas. Das Recht der Gesellschaft. Frankfurt am Main: Suhrkamp, 1993.

LUHMANN, Niklas. La Sociedad de la Sociedad. México: Editorial Herder, S. de R.L. de C.V, 2006.

LUHMANN, Niklas. Sistemas Sociais: esboço de uma teoria geral. Rio de Janeiro: Vozes, 2016.

LUHMANN, Niklas. Social systems. California: Stanford University, 1995.

LUHMANN, Niklas. Sociologia como teoria dos sistemas sociais. In: Pensamento de Niklas Luhmann, col. TA PRAGMATA(org). José Manuel dos Santos. Portugal: Universidade da Beira Interior, 2005. 
MACCORMICK, Neil. Grundlagen des institutionalistischen Rechtpositivismus. Berlim: Duncker \& Humblot Gmbh, 1985.

MATURANA, Humberto; VARELA, Francisco. De máquinas e seres vivos: autopoiese: a organização do vivo. 3. ed. Porto Alegre: Artes Médicas, 1997.

NEVES, Marcelo. A constitucionalização simbólica. São Paulo: Martins Fontes, 2007.

NEVES, Marcelo. Luhmann, Habermas e o estado de direito. Lua nova: Revista Cultura e Política, n 37, p. 93-106, 1998. Disponível em: http://www.scielo.br/pdf//n/n37/a06n37.pdf . Acesso em: 31 jul. 2017.

POSTEMA, J.Gerald. Bentham and the common law tradition. Oxford: Clarendon pass, Oxford Unisity press, 1986. Disponível em:

https:// /www.jstor.org/stable/2380941?seq=1\#page_scan_tab_contents. Acesso em: 8 maio 2017.

POUND, Roscoe. Mechanical Jurisprudence. Gale: Making of Modern Law, 2010.

ROCHA, Leonel Severo. Epistemologia Jurídica e Democracia. São Leopoldo: Unisinos, 1998.

ROCHA, Leonel Severo. Paradoxos da Auto-observação: percursos da teoria jurídica contemporânea. Curitiba: JM, 1977.

SILVA, Artur Stamford da. Decisão jurídica e mudança social. Para uma sociologia da decisão jurídica. confluências- Revista Interdisciplinar de Sociologia e Direito, v. 11, n. 1, p. 143, 2010. Disponível em:

http://www.confluencias.uff.br/index.php/confluencias/article/view/177/21. Acesso em: 15 abr. 2019.

SPENCER-BROWN, George. Laws of form. New York: Dutton, 1979.

STRECK, Lenio Luiz. Um encontro de titãs: Kelsen, Hart \& Cia analisam acórdão do STJ. Revista Consultor Jurídico, 2016. Disponível em: http://www.conjur.com.br/2016-jul-07/sensoincomum-encontro-titas-kelsen-hart-cia-analisam-acordao-stj. Acesso em: 20 fev. 2017.

STRECK, Lenio Luiz. Verdade e Consenso. 5. ed. São Paulo: Saraiva, 2014

SUMMERS, Robert Samuel. Instrumentalism and American Legal Theory. Ithaca, N.Y: Cornell University Press, 1982.

TEUBNER, Günther. 0 direito como sistema autopoiético. Lisboa: Fundação Calouste Gulbekian, 1993.

VILLAS-BÔAS FILHO, Orlando. Teoria dos sistemas e o direito brasileiro. São Paulo: Saraiva, 2009.

WITTGENSTEIN, Ludwig. Investigações filosóficas. São Paulo: Nova Cultural, 1999. 
WITTGENSTEIN, Ludwig. Tractus logico-philosofico. São Paulo: Editora da Universidade de São Paulo, 1988. Disponível em: https://marcosfabionuva.files.wordpress.com/2011/08/tractatuslogico-philosophicus.pdf. Acesso em: 12 maio 2017.

\section{COMO FAZER REFERÊNCIA AO ARTIGO (ABNT):}

SIMIONI, Rafael Lazzarotto; PINTO, João Paulo Salles. Parodoxos na autodescrição do sistema do direito: corrupção sistêmica e o ativismo judicial. Revista Eletrônica do Curso de Direito da UFSM, Santa Maria, RS, v. 14, n. 2, e30746, maio./ago. 2019. ISSN 1981-3694. DOI: http://dx.doi.org/10.5902/1981369430746. Disponível em: https://periodicos.ufsm.br/revistadireito/article/view/30746 Acesso em: dia mês. ano.

Direitos autorais 2019 Revista Eletrônica do Curso de Direito da UFSM

Editores responsáveis: Rafael Santos de Oliveira e Angela Araujo da Silveira Espindola

Este obra está licenciado com uma Licença Creative Commons Atribuição-NãoComercial-SemDerivações 4.0 Internacional.

\section{SOBRE OS AUTORES}

RAFAEL LAZZAROTTO SIMIONI

Pós-Doutor em Filosofia e Teoria do Direito pela Faculdade de Direito da Universidade de Coimbra (2011), Doutor em Direito Público pela Unisinos (2008), Mestre em Direito pela UCS (2005) e graduação em Direito pela UCS. É professor permanente do Programa de Pós-Graduação em Direito da Faculdade de Direito do Sul de Minas-FDSM, professor colaborador do Programa de Pós-Graduação em Bioética da Universidade do Vale do Sapucaí-Univás e professor convidado do Programa de Pós-Graduação em Educação da Universidade Estadual de Campinas-Unicamp. Coordenador do Programa de Pós-Graduação em Direito da FDSM. Pesquisador-líder do Grupo de Pesquisa Margens do Direito (PPGD/FDSM). Teoria, filosofia e sociologia do direito são suas principais áreas de interesse.

\section{João Paulo SAlles Pinto}

Mestre em Direito pela Faculdade de Direito do Sul de Minas- FDSM (2017), tendo cursado o mestrado com bolsa de pósgraduação stricto sensu PROSUP. CAPES. Teoria, filosofia e sociologia do direito são suas principais áreas de interesse e pesquisa. Graduado em Direito pelo Instituto Machadense de Ensino Superior- IMES (2015). Autor do Livro: Corrupção Sistêmica e Direitos Humanos: o lugar do paradoxo na autodescrição do direito (2018) publicado pela editora Juruá. 